\title{
IMPLEMENTASI SISTEM INFORMASI PEMESANAN MENU MAKANAN DAN MINUMAN PADA KAFE BERBASIS WEB MENGGUNAKAN JARINGAN INTRANET
}

\author{
Nia Caniati ${ }^{1)}$, Ahmad Lubis Ghozali ${ }^{2}$, A. Sumarudin ${ }^{3)}$ \\ 1)2)3) Program Studi Teknik Informatika \\ Politeknik Negeri Indramayu \\ J1. Raya Lohbener Lama No.8 Lohbener Indramayu Barat Indonesia \\ niacaniati26@gmail.com ${ }^{1)}$, lubis@polindra.ac.id ${ }^{2)}$, shumaru@polindra.ac.id ${ }^{3)}$
}

\begin{abstract}
ABSTRAK
Kafe merupakan tempat untuk bersantai dan berbincang-bincang dimana pengunjung dapat memesan minuman dan makanan. Pada umumnya restoran ataupun kafe mengalami kesulitan untuk melayani pemesanan menu makanan dan minuman, kesulitan tersebut adalah pelanggan menunggu terlalu lama untuk mendapatkan menu makanan dan minuman yang dipesan sehingga kurang adanya kenyamanan bagi pengunjung. Implementasi sistem informasi pemesanan menu makanan dan minuman ini diterapkan berbasis web dengan menggunakan jaringan intranet bertujuan agar operasional kafe dapat berjalan lebih efektif, aman, cepat, dan akurat. Dengan sistem informasi ini data laporan penjualan kafe menjadi terkomputerisasi, sehingga data dapat tersimpan dengan baik. Sistem informasi ini dikembangkan menggunakan framework bootstrap dengan bahasa pemrograman PHP dan menggunakan database MySQL. Dari hasil pengujian menggunakan metode blackbox dapat disimpulkan bahwa sistem informasi pemesanan menu makanan dan minuman berbasis web ini dapat membantu proses pemesanan pada salah satu kafe Made In Bandung.
\end{abstract}

Kata Kunci: sistem informasi, pemesanan menu, kafe, jaringan intranet, website.

\begin{abstract}
The cafe is the place to relax and chat where visitors can order drinks and food. In the common restaurant or café there is difficulty serving the food and beverage menu reservations, the difficulty is that customers wait too long to get food and drink menus ordered to the lack of visitor comfort. Implementation of food and beverage order information system is implemented through the web using an intranet network aimed at running cafes that can run more effectively, safely, quickly, and accurately. With this report data sales system data becomes a computer cafe, so that data can be stored properly. This information system was developed using bootstrap framework with PHP programming language and used MySQL database. From the results of the test using the blackbox method it can be concluded that menu menu of food information and beverage based on this web can help the ordering process in one of Made Cafes Bandung.
\end{abstract}

Keywords: information system, order menu, cafe, intranet network, website. 


\section{PENDAHULUAN}

Kafe merupakan tempat untuk bersantai dan berbincang-bincang dimana pengunjung dapat memesan berbagai macam menu minuman dan makanan. Pada umumnya restoran ataupun kafe mengalami kesulitan untuk melayani pemesanan menu makanan dan minuman, kesulitan tersebut adalah pelanggan menunggu terlalu lama untuk mendapatkan menu makanan dan minuman yang dipesan sehingga kurang adanya kenyamanan bagi pengunjung.

Selain itu pelayan juga mengalami kesulitan ketika menanyakan pesanan menu dari pelanggan yang dicatat secara manual menggunakan kertas. Pencatatan pesanan menu secara manual kurang efisien dari sisi waktu, dan kemungkian sering terjadi kesalahan dalam pembuatan pesanan, namun hal tersebut dapat dikurangi dengan adanya kemajuan dan penggunaan teknologi mobile, untuk melakukan pemesanan menu makanan dan minuman dengan menggunakan jaringan intranet berbasis website.

Pemanfaatan teknologi mobile yang disetiap meja terdapat tablet sebagai pengganti daftar menu dan harga tersebut bagi pengunjung kafe dianggap efektif karena tidak harus datang ke dapur dan ke kasir untuk memberitahu pesanan menu dari pelanggan, melainkan dapat dipilih dan di input secara langsung melalui tablet yang sudah disediakan di meja pelanggan. Oleh karena itu konsep yang ditawarkan dalam penelitian ini melalui peralatan mobile berbasis website yang dikirim ke server selanjutnya diteruskan ke kasir dan dapur.

Pemesanan menu di kafe atau restoran menggunakan peralatan mobile tersebut dapat mengurangi keterlambatan atau terlalu lama mengantar pesanan menu kepada pelanggan.

Salah Satu restoran ataupun cafe yang menjadi objek penelitian ini adalah Kafe Made In Bandung yang beralamat di Jalan Sariasih II No. 48 Sarijadi Bandung. Tujuan dari penerapan aplikasi ini, agar operasionalnya menjadi lebih efektif, cepat dan akurat.

Sehingga hal ini menjadi landasan utama pentingnya dilakukan penelitian mengenai Implementasi sistem informasi pesanan menu minuman dan makanan berbasis web yang diterapkan menggunakan jaringan intranet. Karena teknologi informasi ini akan mendukung semua kegiatan menjadi lebih mudah, data tidak akan hilang ataupun rusak dan usang, data dapat disimpan dengan aman, dan masih banyak lagi keuntungan lain dari teknologi informasi.

\section{TINJAUAN PUSTAKA}

Sistem Informasi berbasis web dalam penelitian yang sudah dilaksanakan oleh beberapa peneliti, banyak menghasilkan sebuah produk atau sistem berbasis web, seperti sistem informasi yang mempunyai kemampuan dalam análisis guna untuk menampilkan data sebagai pendukung sebuah keputusan terhadap end user yang ditampilkan sesuai dengan keinginan end user itu sendiri, hasil pengolahan data dapat ditampilkan dalam bentuk tabel, grafik, dan dashboard yang dapat digunakan sebagai bahan evaluasi oleh pihak Institusi pendidikan [4].

Penerapan Sistem Informasi sebenarnya sudah banyak dilakukan oleh para peneliti, namun dalam penelitian ini penulis lebih menyederhanakan konsep data warehouse yang dapat dianggap sebagai suatu salinan data transaksional atau OLTP yang terstruktur untuk kebutuhan analisis, reporting, dan data mining. Oleh karena itu, sistem transaksi tidak pernah meng-update data yang berada di dalam data warehouse melainkan hanya menambahkan data ke dalam data warehouse tersebut. Berikut ini pada Tabel 2.1 memperlihatkan perbedaan sistem OLTP dan sistem data warehouse [1].

Table 1. Perbedaan OLTP dan Data Warehouse [1]

\begin{tabular}{|l|l|}
\hline \multicolumn{1}{|c|}{ OLTP } & \multicolumn{1}{c|}{ Data Warehouse } \\
\hline Menangani data saat ini & $\begin{array}{l}\text { Lebih cenderung menangani } \\
\text { data masa lalu }\end{array}$ \\
\hline $\begin{array}{l}\text { Data disimpan pada } \\
\text { beberapa platform }\end{array}$ & $\begin{array}{l}\text { Data disimpan dalam satu } \\
\text { platform }\end{array}$ \\
\hline $\begin{array}{l}\text { Data diorganisasi } \\
\text { berdasarkan fungsi atau } \\
\text { operasi, seperti } \\
\text { penjualan, produksi, } \\
\text { dan pemrosesan } \\
\text { pesanan }\end{array}$ & $\begin{array}{l}\text { Data diorganisasi menurut } \\
\text { subyek seperti pelanggan } \\
\text { atau produk }\end{array}$ \\
\hline $\begin{array}{l}\text { Pemrosesan bersifat } \\
\text { berulang }\end{array}$ & $\begin{array}{l}\text { Pemrosesan sewaktu-waktu, } \\
\text { tidak terstruktur, dan } \\
\text { bersifat heuristic }\end{array}$ \\
\hline $\begin{array}{l}\text { Untuk mendukung } \\
\text { keputusan harian } \\
\text { (operasional) }\end{array}$ & $\begin{array}{l}\text { Untuk mendukung } \\
\text { keputusan yang strategis }\end{array}$ \\
\hline $\begin{array}{l}\text { Melayani banyak } \\
\text { pemakai opersional }\end{array}$ & $\begin{array}{l}\text { Untuk mendukung pemakai } \\
\text { manajerial yang berjumlah } \\
\text { sedikit }\end{array}$ \\
\hline $\begin{array}{l}\text { Berorientasi pada } \\
\text { transaksi }\end{array}$ & Berorientasi pada analisis \\
\hline
\end{tabular}

MySQL adalah Relational Database Management System (RDBMS) yang didistribusikan secara gratis di bawah lisensi GPL (General Public License). MySQL merupakan turunan dari salah satu konsep utama dalam database sejak lama yaitu SQL (Structured Query Language). SQL adalah sebuah konsep pengoperasian database, terutama untuk pemilihan atau seleksi dan pemasukan data, yang memungkinkan pengoperasian data dikerjakan dengan mudah secara otomotis. MySQL dapat dikatakan lebih unggul dibandingkan database server lainnya dalam query data. Hal ini terbukti untuk query yang dilakukan oleh single user, kecepatan query MySQ1 bisa sepuluh kali lebih cepat dari PostgreSQL dan lima kali lebih cepat dibandingkan Interbase [4].

Intranet adalah sebuah jaringan di dalam sebuah organisasi yang menggunakan teknologi internet 
(seperti web browser dan server, TCP/IP protokol jaringan, penerbitan dokumen HTML hypermedia dan database, dan lainnya) untuk menyediakan lingkungan internet dalam perusahaan untuk berbagi informasi, komunikasi, kolaborasi, dan dukungan dari proses bisnis [2].

Intranet adalah jaringan perusahaan ataupun pemerintah yang menggunakan tools dalam internet, seperti web browser dan internet protocol. Jaringan intranet ini akan digunakan perusahaan sebagai media komunikasi dan kolaborasi [5].

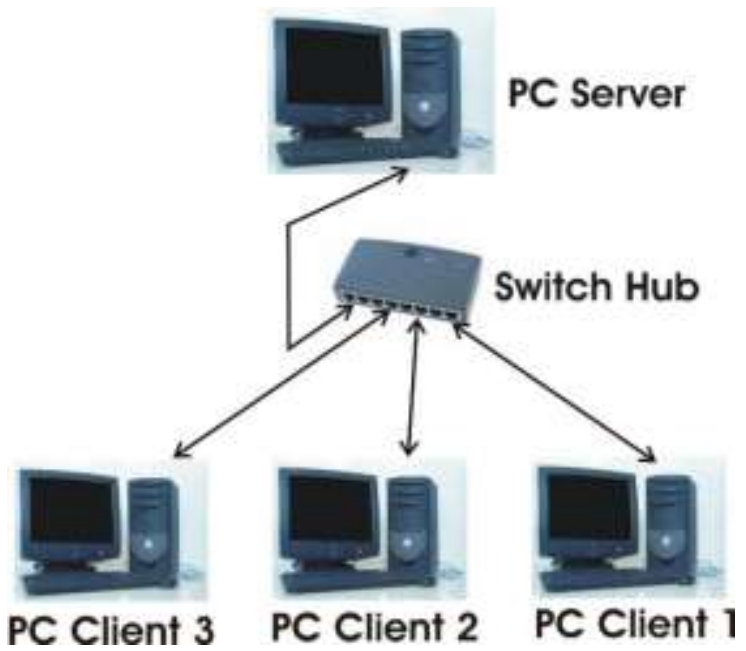

Gambar 1. Simulasi jaringan Intranet [6]

\section{METODE PENELITIAN}

Dalam melakukan penelitian ini penulis menggunakan metode studi literatur dan studi lapangan yaitu dengan memahami landasan teori mengenai segala hal yang berkaitan dengan penelitian serta melakukan wawancara langsung dengan pihak yang terkait dengan implementasi sistem informasi ini.

Untuk metode pengembangan sistem informasi ini sendiri menggunakan model flowchart agar lebih mudah dalam penanganan error ataupun dalam penambahan fungsi-fungsi lain.

Dalam perancangan Aplikasi ini terdiri dari beberapa tahapan yaitu pengumpulan data, analisis kebutuhan, perancangan sistem, perancangan database, dan perancangan interface.

\section{Pengumpulan Data}

Pengumpulan data pada penelitian ini dilakukan dengan mengumpulkan data-data menu dari kafe yang terkait dan pengambilan data langsung dari kafe made in bandung yang beralamat Jl. Sariasih II No.48 Sarijadi Bandung.

\section{Analisis Kebutuhan}

Kebutuhan sistem dalam pengembangan aplikasi ini terbagi menjadi 2 yaitu hardware dan software.
Adapun kebutuhan dalam penerapan aplikasi ini dapat kita lihat pada tabel dibawah ini.

Tabel 2. Kebutuhan Hardware.

\begin{tabular}{|c|c|c|}
\hline No & Jenis Hardware & Kebutuhan Hardware \\
\hline 1 & Processor & $\begin{array}{l}\text { Minimum Intel atau } \\
\text { AMD Dual Core }\end{array}$ \\
\hline 2 & Hard disk & $50 \mathrm{~GB}$ \\
\hline 3 & RAM & Minimum $1 \mathrm{~GB}$ \\
\hline 4 & $\begin{array}{l}\text { Smartphone } \\
\text { Tablet }\end{array}$ & Android 4.2 (kitkat) \\
\hline 5 & Access Point & Linksys E1700 \\
\hline
\end{tabular}

Tabel 3. Kebutuhan Software.

\begin{tabular}{|c|c|l|}
\hline No & Jenis Software & \multicolumn{1}{|c|}{ Kebutuhan Software } \\
\hline 1 & Sistem Operasi & $\begin{array}{l}\text { Minimum Microsoft } \\
\text { Windows XP, lebih baik } \\
\text { windows 7 ke atas }\end{array}$ \\
\hline 2 & $\begin{array}{c}\text { Bahasa } \\
\text { Pemrogaman }\end{array}$ & $\begin{array}{l}\text { Boostrap, PHP } \\
\text { (Hypertext } \\
\text { preproccesor) }\end{array}$ \\
\hline 3 & $\begin{array}{c}\text { Software } \\
\text { Pengolah }\end{array}$ & $\begin{array}{l}\text { Sublime Text 3, dan } \\
\text { PhpMyAdmin }\end{array}$ \\
\hline 4 & $\begin{array}{c}\text { Penyimpanan } \\
\text { Data }\end{array}$ & Database (MySQL) \\
\hline 5 & Web Browser & $\begin{array}{l}\text { Mozilla Firefox dan } \\
\text { Google Chrome }\end{array}$ \\
\hline
\end{tabular}

\section{Perancangan Sistem}

Dalam penerapan Aplikasi ini perancangan sistem yang digunakan adalah UML (Unified Modelling Language). Use case diagram adalah gambaran graphical dari beberapa atau semua actor, use case dan interaksi diantara komponenkomponen yang memperkenalkan suatu sistem yang akan dibangun dan digunakan untuk menjelaskan bagaimana langkah-langkah yang seharusnya dikerjakan oleh sistem.

Adapun dalam aplikasi ini memiliki 4 type access yaitu pelanggan/client, kasir, dapur, dan admin.

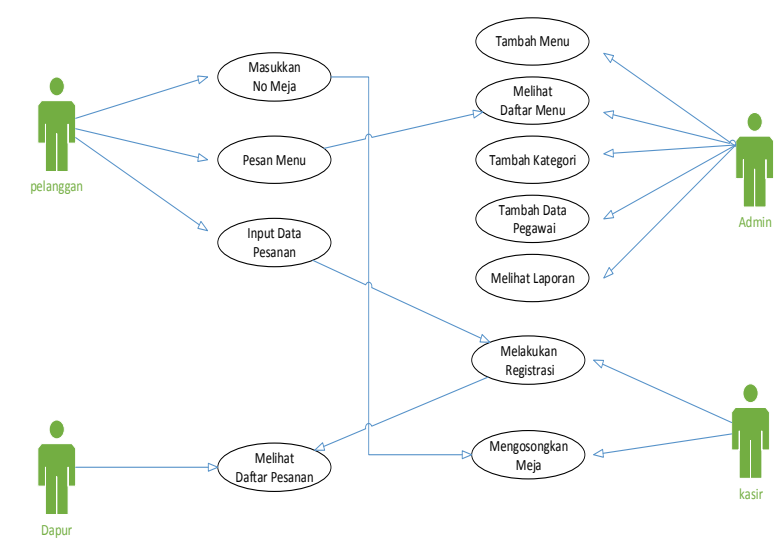

Gambar 2. Use Case Diagram 


\section{Perancangan Database}

Data pemesanan yang ditampilkan pada aplikasi ini memiliki 4 bagian user yaitu: Pelanggan, kasir, dapur, dan admin. Adapun perancangan database dapat dilihat pada gambar dibawah ini.

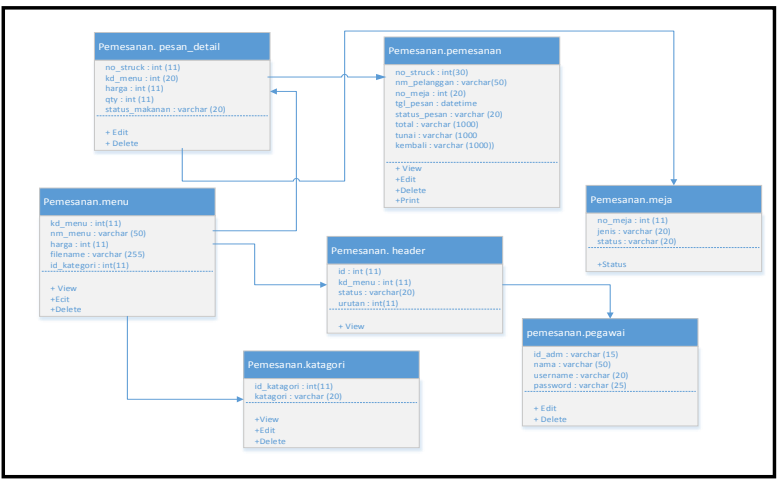

Gambar 3. Rancangan Database

\section{Desain Interface}

Interface dari Implementasi Sistem Informasi Pemesanan Menu Makanan dan minuman pada Kafe made in bandung menggunakan Framework Bootstrap dan PHP. Interface pada aplikasi ini terdapat 4 halaman : Halaman pelanggan, kasir, dapur, dan admin.

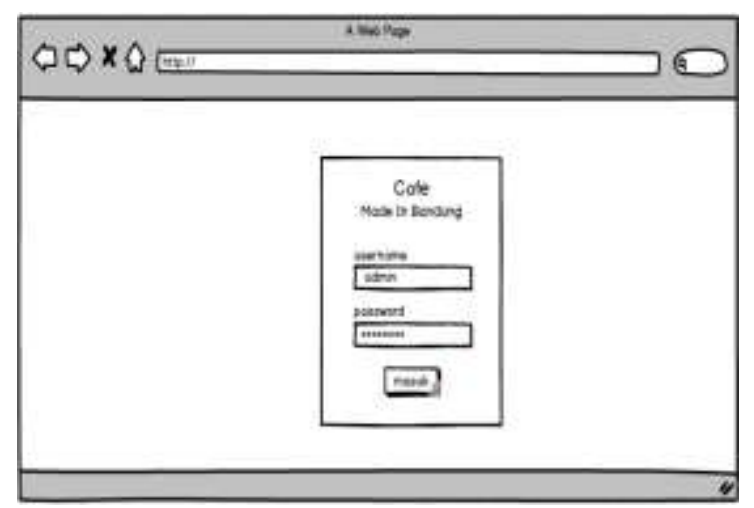

Gambar 4. Rancangan tampilan login

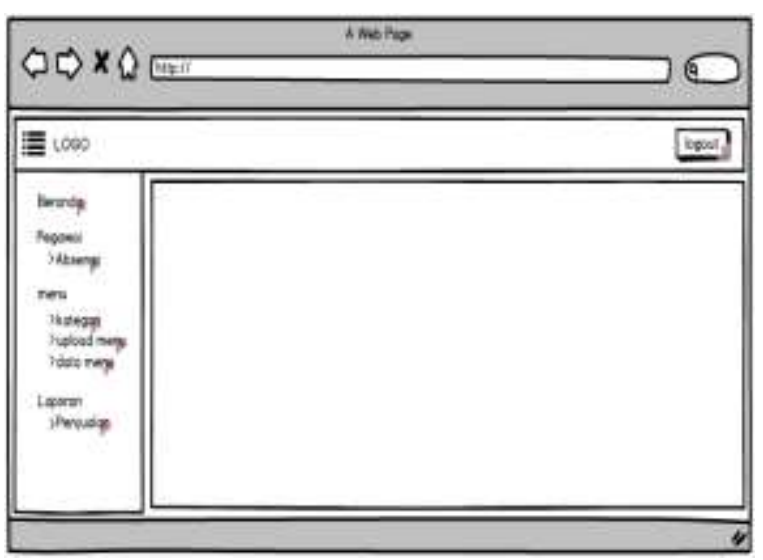

Gambar 5. Rancangan Tampilan Admin

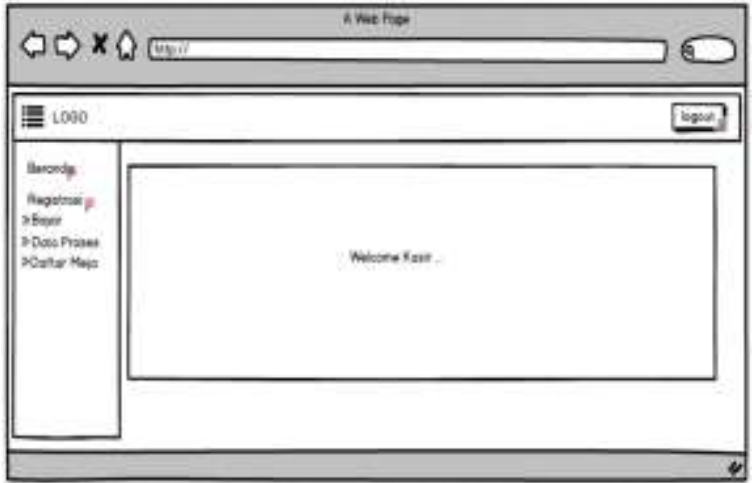

Gambar 6. Rancangan Tampilan Kasir

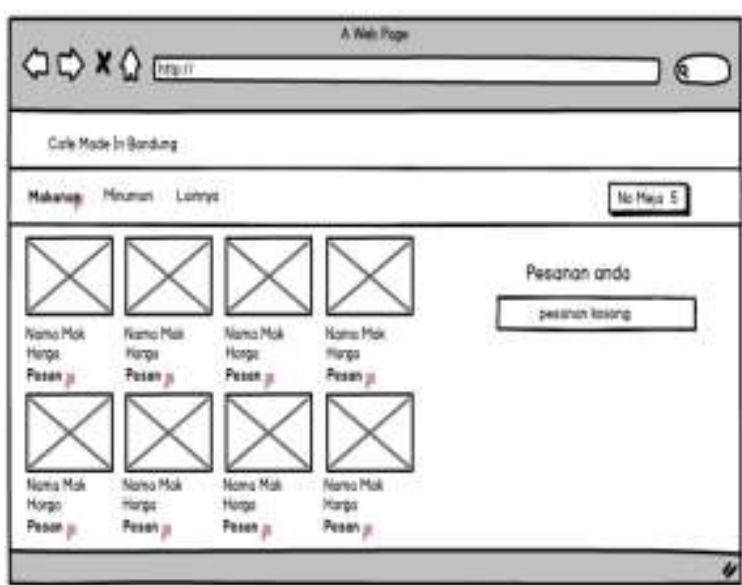

Gambar 7. Rancangan Tampilan Pelanggan

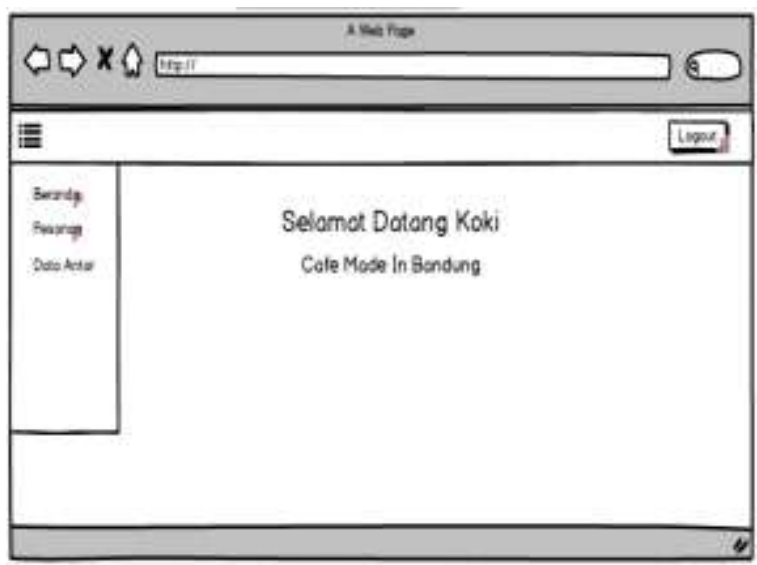

Gambar 8. Rancangan Tampilan Dapur

\section{HASIL PENELITIAN}

Penelitian ini menghasilkan sebuah aplikasi pemesanan menu makanan dan minuman berbasis web pada café made in bandung dengan jaringan intranet. Aplikasi ini mempunyai 3 type akses antara lain pelanggan, kasir, dapur, dan admin. Selain itu, seperti yang telah dijelaskan pada bab sebelumnya dalam aplikasi ini menggunakan jaringan intranet.

Adapun dari 3 type access yang tersedia mempunyai batasan-batasan akses yang telah ditentukan. Hak akses pengunjung user membuka halaman tanpa memasukan username dan password 
(tidak perlu login), pelanggan dapat memasukkan no meja dan nama, memilih menu yang akan dipesan.

Hak akses kasir adalah hak akses yang bertugas mengolah registrasi/pembayaran data pesanan dan mencetak nota, serta mengkonfirmasi pesanan yang akan dimasak dengan melakukan login terlebih dahulu. Hak akses dapur adalah hak akses yang bertugas memasak data-data pesanan yang sudah dikonfirmasi di bagian dapur, sebelum mengakses halaman dapur user melakukan login terlebih dahulu. Hak akses admin adalah hak akses yang bertugas mengolah data semua user seperti menambahkan menu-menu pada halaman pelanggan, mengontrol data laporan penjualan, dan menambahkan pegawai dan lainnya.

Berikut ini adalah hasil tampilan dari perancangan dan penerapan aplikasi pemesanan menu makanan dan minuman berbasis web pada café made in bandung dengan jaringan intranet.

\section{Pelanggan}

\section{Cafe Made in Bandung}

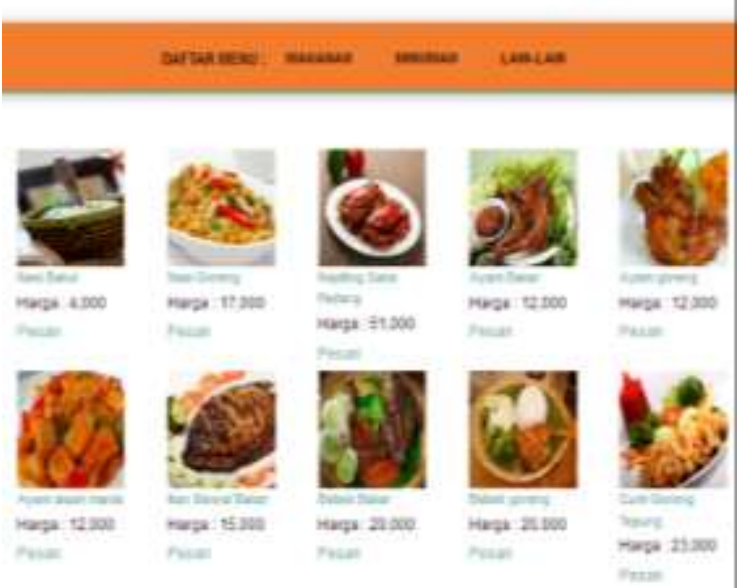

Gambar 9. Tampilan home pelanggan

\section{Pesanan Anda}

2017-08-98 04:16:4

\begin{tabular}{|c|c|c|c|c|}
\hline Hama Menu & Harga & Qty & Jumlah & Aksi \\
\hline Ayam goreng & Ap. 12,000 & 1 & Rp.12000 & $=1-1$ Haps: \\
\hline Bebek goreng & Ap. 20,003 & 1 & Ap. 20,050 & +1 -I Haves \\
\hline \multirow[t]{2}{*}{ Bebek Bakar } & Ap. 20,80$]$ & 1 & Rp. 20080 & $+1-1$ Hages \\
\hline & & & Rp.520000 & Clea PESAN \\
\hline
\end{tabular}

Gambar 10. Tampilan pesanan pelanggan

Pada halaman pelanggan, terdapat menu-menu yang sudah tersedia pada kafe made in bandung dan terdapat data pesanan menu yang dipesan.

\section{Kasir}

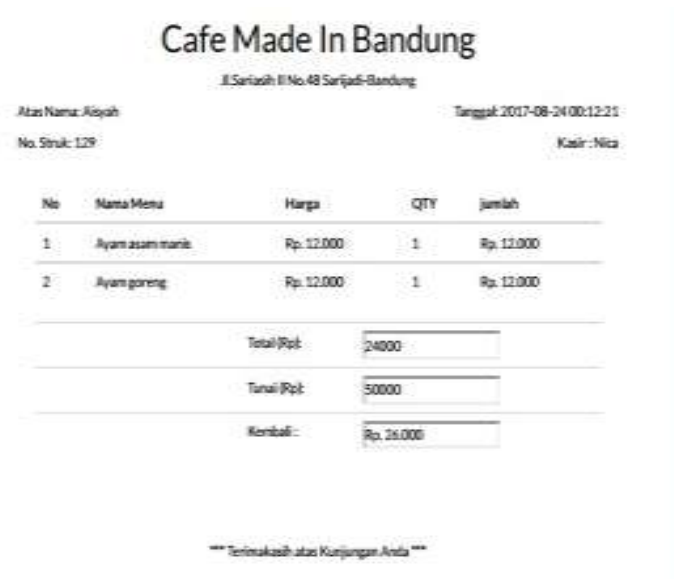

Gambar 11. Tampilan Nota

Pada halaman ini kasir dapat mencetak nota sebagai bukti pembayaran pelanggan.

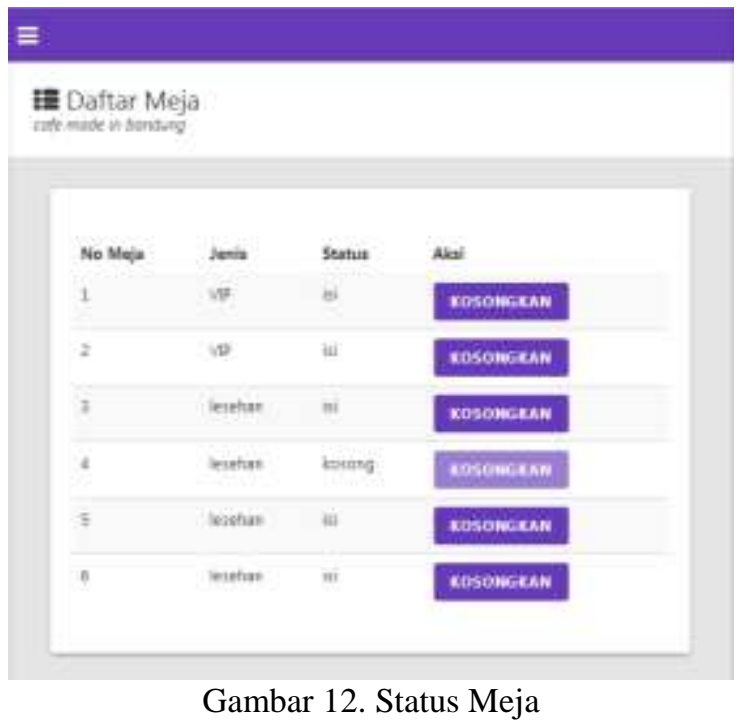

Pada halaman kasir ini terdapat tampilan untuk mengosongkan meja apabila meja sudah kosong supaya bisa terisi oleh pesanan selanjutnya.

\section{Dapur}

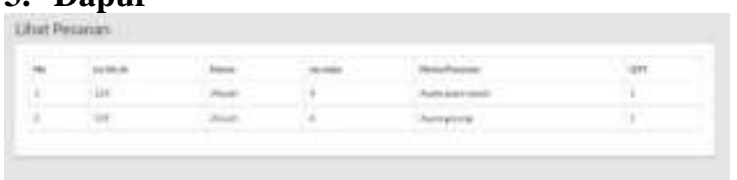

Gambar 13. Lihat Pesanan

Pada halaman Dapur terdapat menu untuk melihat daftar pesanan yang akan dimasak.

\section{Admin}

Pada halaman admin terdapat halaman untuk menambahkan menu makanan dan minuman. Yang kemudian akan ditampilan pada halaman pelanggan dan daftar menu pada admin. 


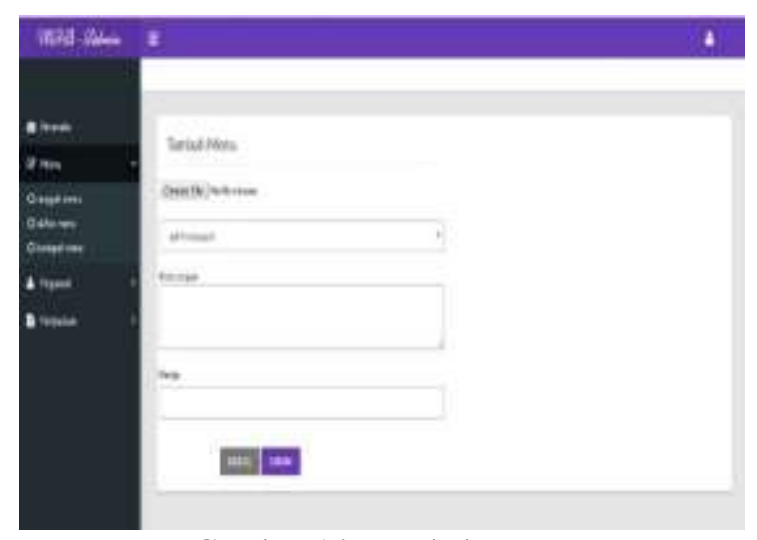

Gambar 14. Tambah Menu

\section{Pengujian Akses Aplikasi pada Jaringan Intranet}

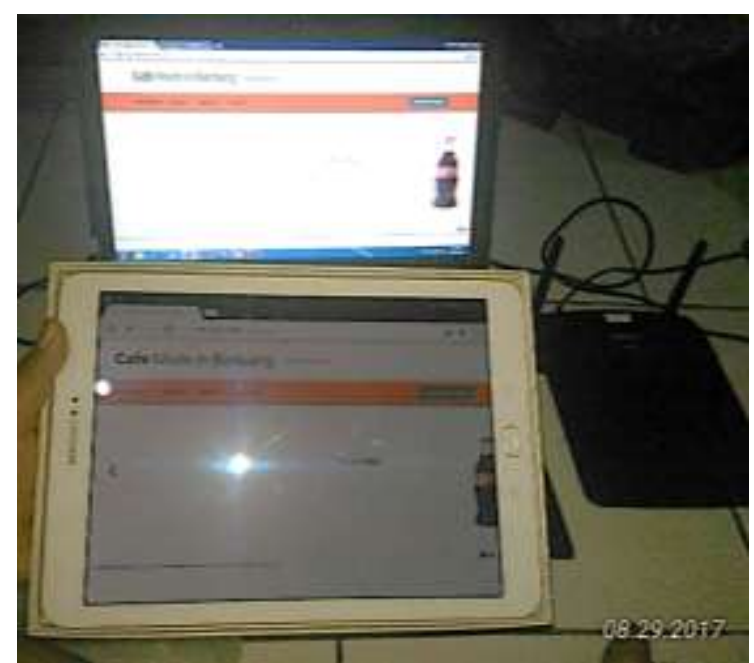

Gambar 15. Penerapan ke Jaringan Intranet

\section{KESIMPULAN}

Dari semua pembahasan yang telah dijelaskan pada poin-poin sebelumnya, maka penulis menarik kesimpulan sebagai berikut:

a. Sistem Informasi pemesanan menu makanan dan minuman berhasil diimplementasikan sesuai rancangan yang sudah dibuat.

b. Berdasarkan pengujian yang telah dilakukan, proses sistem informasi pemesanan menu makanan dan minuman berjalan sesuai rancangan.

c. Berdasarkan hasil pengujian sistem informasi pemesanan menu makanan dan minuman pada jaringan intranet berhasil diakses.

d. Sistem yang dapat berjalan tersebut berdasarkan pertimbangan peralihan dari sistem lama ke sistem baru, sehingga masih ada penyesuaian dalam penerapannya pada kafe Made in Bandung.

\section{DAFTAR PUSTAKA}

[1] Kadir, A., 2003, Pengenalan Sistem Informasi, Penerbit Andi Publisher, Yogyakarta.

[2] O’Brien, James A. dan Marakas, George M. 2011. "Management Information Systems, 10th Edition". McGraw-Hill/ Irwin, New York.

[3] Ghozali, A.L. dan Mustafid, dan Farikhin. 2014. "Sistem Informasi Pendukung Keputusan Terhadap Mutu Lulusan dengan Metode Fuzzy Model Tsukamoto”. Jurnal Sistem Informasi Bisnis. Undip Semarang, vol. 4, no. 2, pp. 87-95.

[4] Ghozali, A.L. dan Bunga, M.S. 2017 "Implementasi Sistem Business Intelligence Terhadap Rekap Nilai Perkuliahan Menggunakan Metode Online Analitycal Processing (OLAP)", Semnasteknomedia Online, 5(1), 1-2.

[5] Turban, E., King, D., Lee, J., Liang, T.P., and Turban, D. 2010. Electronic Commerce : A Managerial Perspective, Pearson, New Jersey.

[6] Sujono Riyadi, S. M. 2011. Buku Keperawatan Medikal Bedah. Pustaka Pelajar: Yogyakarta. 